\title{
Loss of anti-predator behaviors in cattle and the increased predation losses by wolves in the Northern Rocky Mountains
}

\author{
Cornelia Flörcke *, Temple Grandin \\ Department of Animal Sciences, Colorado State University, Fort Collins, USA; \\ *Corresponding Author: conny.floe@gmx.de, Cheryl.Miller@colostate.edu
}

Received 19 May 2013; revised 20 June 2013; accepted 28 June 2013

Copyright (C 2013 Cornelia Flörcke, Temple Grandin. This is an open access article distributed under the Creative Commons Attribution License, which permits unrestricted use, distribution, and reproduction in any medium, provided the original work is properly cited.

\begin{abstract}
Managing livestock near Yellowstone National Park has become an increasing challenge since conservation of wolves restricts ranchers from interfering. Even though wolves are beneficial for the ecosystem, rising predation incidences on livestock (depredations) create animosity in local farmers. Temperament selection of cattle, measured by the facial hair whorl pattern $(\mathrm{HW})^{1}$, occurred during the last $\mathbf{1 5}$ years and the industry prefers calmer temperament animals. Six HWs occur in cattle (high, middle, low, abnormal, multiple and none), which are mutually exclusive and can be identified by using the eye-line as a reference point. We analyzed depredation of calves near Council, ID in 2011. A herd of 588 Black Angus $\times$ Charolais crossbreds (age range: 5 - 17 years) was observed. By analyzing the HW and age of cows in relation to depredations, we could identify a connection between these three factors $(P<0.001)$. The HW of a cow influenced the probability of losing the calf to predation ( $P$ $<0.001$ ). Cows without the facial HW faced an increased percentage of losses (probability of $19.6 \%$ of losing the calf) compared to other HW (probability between $0 \%-6.1 \%$ ). An age effect on the probability of losing the calf was also found $(P=0.023)$. Cows over the age of 10 years are more likely to lose their calves. Our findings suggest that behavioral differences between cows with different HWs exist. Differences in protectiveness or vigilance towards the surroundings in cows without a facial HW may lead to an increased probability of losing their calves.
\end{abstract}

${ }^{1} \mathrm{HW}=$ hair whorl pattern.
Keywords: Cattle; Depredation; Hair Whorl Pattern; Temperament Selection; Wolves (Canis lupus)

\section{INTRODUCTION}

A natural conflict arises when the home ranges of predator and prey species overlap. By reintroducing Canadian gray wolves (Canis lupus) in Yellowstone National Park (YNP) and Central Idaho in 1995/96 [1] naïve prey species were suddenly exposed to predation. Wolves were extinct in YNP and surrounding areas for 70 years. Elk (Cervus elaphus) and mule deer (Odocoileus hemionus) populations reproduced intensely during this period, thereby over-browsing riparian sites and various tree species [2,3]. A trophic cascade occurred by reintroducing wolves [4]. Wolf populations decreased elk and deer numbers which, as a result, released the next lower trophic species of cottonwoods, aspen and willows from suppression [5,6]. A detailed map of the complexity of interactions in YNP can be found in Smith et al., 2003 [7]. The change in predator-prey species abundance was beneficial for the ecosystem [8]. In YNP and Idaho, wolves were mainly preying on elk (90\%) and only occasionally killed livestock [7,9]. Overall, the reintroduction was seen as a great success because wolf populations became established after only two years [10] instead of the predicted 3 - 5 years after reintroduction.

The almost exponential reproduction of wolves resulted in increased predation losses of livestock, called depredation. Stalking, harassment and depredation of wolves on domestic livestock is creating public concerns, causes financial problems for ranchers and animosity [11]. Overall, livestock depredations are minimal but the ramifications for an individual producer are significant because depredations are not distributed evenly. Certain producers experience higher losses than others [12] cre- 
ating a challenge for wolf conservation and management in these areas [11]. In the presence of wolves, wild ungulates change their behavior [13,14] and movement patterns to avoid predation [15]. Anti-predator behaviors of elk during summer months include habitat changes by moving to higher elevations with steeper slopes [16,17] and increasing the group size [18-20]. Due to increased fear, prey animals also increase their vigilance level [21-24]. With elk being out of reach during summer months, wolves start to prey on livestock [25].

Anti-predator behaviors of our domesticated livestock species, such as cattle and sheep, are however poorly developed because of artificial selection towards calmness over many generations [26,27]. Most livestock species do not regularly face predators and show weak or no response to predator presence compared to wild ungulates [28]. Welp et al., 2004 [29] reported vigilance levels of dairy cows as a potential measure of fear. Cows in their experiment differed in vigilance level based on the environment and novelty of the stimulus. In general, cattle vigilance is increased and foraging behaviors decreased when wolf stimuli are present; contrariwise, vigilance decreases when deer stimuli are presented [30]. The former study was able to shed light on the connectedness of ungulate-predator behaviors. Other research found that the vigilance level after parturition of beef cattle varies according to the facial hair whorl position (HW) of the cow [31]. Cows with middle spiral HW and multiple HWs pay more attention to their surrounding and react earlier to an unknown approaching object (at a greater distance) than cows with other HWs [31]. Increased vigilance in areas with high predation pressure could potentially make the difference between life and death for an animal. The facial HW is frequently used as a measure of temperament and can be identified easiest when the animal is in a squeeze chute [32,33]. Limousine breeders were using temperament selection during the last 15 years, thereby altering and improving the docility of cattle [34].

Advantages of temperament selection are higher average daily gain of calmer cattle [35], improved human-cattle interactions [36], easier transport [37] and reduced fear [38]. However, recent increases in depredation raise the question if we out-selected protectiveness and fearfulness of our livestock species. The present study tries to identify a connection between the temperament of an animal, measured by the facial HW, and depredation losses of cattle in areas with increased predation.

\section{MATERIAL AND METHODS}

Observations were made in compliance with Colorado State University Animal Care and Use Committee Protocol IACUC \# 10-2267A.

\subsection{Animals and Environment}

This study was conducted on a commercial cow-calf ranch near Council, Idaho, USA, in December 2011. The age range of cows was 5 - 17 years (average age: 7.4 years) and the total herd consisted of 588 cows (commercial Black Angus $\times$ Charolais crossbreds). During winter months, cows graze at lower elevations close to the barn (public land: 15.000 acres, deeded land: 5.000 acres) and are fed supplement and hay. During summer months cows graze at higher elevations on public and deeded land (public land: 120.000 acres, deeded land: 20.000 acres). Summer pastures consist of steep slopes and rough terrain which can only be accessed on horseback in most areas. Wolves represent the main predator during summer months and frequently injure and kill calves and even cows since grazing pastures and wolf territories overlap.

\subsection{Cow Age and Hair Whorl Pattern (HW) Collection}

Age and HW on the forehead of all cows were recorded while cows were in a squeeze chute for pregnancy diagnoses. The experimenter identified the HW position and drew it on a piece of paper. Hair whorls were classified as being high, middle or low position [32]. Using the eye-line as a reference point, HW were further classified as being abnormal, multiple (more than one, all with a clear center) or none (no HW on forehead). Classifications are mutually exclusive and animals were classified into one of these six groups.

\subsection{Statistical Analyses}

All data was analyzed using SPSS 20.0 (SPSS, Inc.). A binomial logistic regression was performed to analyze the probability of losing a calf. The dependent variable in the model is the "loss of a calf" ( $1=$ alive $/ 0=$ dead). Covariates are the hair whorl pattern (high, middle, low, abnormal, multiple and none) and the age of the cow (age range: 5 - 17 years). The logistic regression allows calculating the probability of losing a calf due to the hair whorl pattern and age of the cow. A Wald chi-square test is integrated in the model to indicate how well the logistic regression fits the data. The significance level was set to $\mathrm{P}<0.05$ for this study.

\section{RESULTS}

By analyzing the HW pattern and age of cows in relation to depredations, we could identify a connection between these three factors $(\mathrm{P}<0.001)$. The numbers and percentages of cows in each $\mathrm{HW}$ group are shown in Table 1. The average age of a cow in this herd was 7.4 years. 
Table 1. Distribution of hair whorl pattern in the observed herd and distribution of calves alive/dead observed in 2011.

\begin{tabular}{cccccc}
\hline $\begin{array}{c}\text { Hair Whorl } \\
\text { Pattern }\end{array}$ & n & Alive & Alive in \% & Dead & Dead in \% \\
\hline High & 35 & 34 & $97.1 \%$ & 1 & $2.9 \%$ \\
Middle & 214 & 201 & $93.9 \%$ & 13 & $6.1 \%$ \\
Low & 179 & 171 & $95.5 \%$ & 8 & $4.5 \%$ \\
Abnormal & 53 & 53 & $100 \%$ & 0 & $0 \%$ \\
Multiple & 51 & 48 & $94.1 \%$ & 3 & $5.9 \%$ \\
None & 56 & 45 & $80.4 \%$ & 11 & $19.6 \%$ \\
Overall & 588 & 552 & $93.9 \%$ & 36 & $6.1 \%$ \\
\hline
\end{tabular}

\subsection{Calf Losses by HW Pattern}

The average percentage of losing a calf to predation varied with the HW ( $\mathrm{P}<0.001$; Table 1). Even though cows with middle and low HW are numerically represented highest in the herd, the total number of losses within these two groups was relatively low. No cows with an abnormal HW lost a calf in 2011. The group of cows without a HW, on the other hand, lost $19.6 \%$ of calves.

\subsection{Calf Losses by Cow Age}

The age of the cow further influences the probability of losing the calf due to predation $(\mathrm{P}=0.023)$. Figure 1 shows the probability of losing the calf in relationship to the age and HW of the cow. Cows in the age range of 5 to 10 years with high, middle, low, abnormal or multiple HWs have a probability between $2 \%-8 \%$ of losing the calf to predation. Cows without a HW have a much higher probability of losing the calf starting at $15 \%$ and increasing up to 25\%. The overall distribution of calf losses by the age of cows is shown in Table 2. Twenty young cows in the age of five and six years lost their calf, only a few middle aged cows were subject to predation and ten cows at age 14 lost their calf.

\section{DISCUSSION}

We identified a connection between the facial hair whorl (HW) pattern as well as the age of the cow and the probability of losing the calf to predation. The type of $\mathrm{HW}$ on the forehead of the cow can be associated with the probability of losing the calf. In our study, cows with high and abnormally shaped HW had the least number of losses in the herd. This may be explained by the increased vigilance of cows with high and abnormal HW as observed in the research of Flörcke et al., 2012 [31]. Cows in the former study paid more attention to their surroundings, thereby allowing themselves and their calf

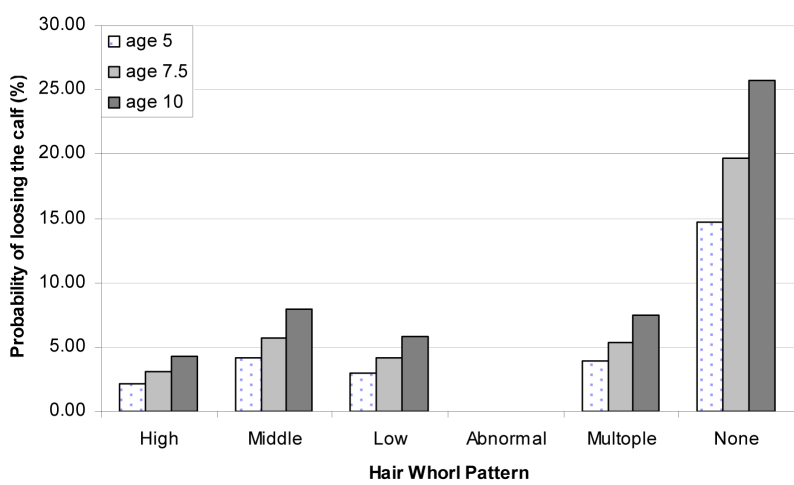

Figure 1. Probability of losing the calf to predation based on the age and the hair whorl position of the cow. Presented are probabilities for losing the calf for the age groups 5, 7.5 (average age of a cow in this herd) and 10 years. Probabilities for cows with an abnormal hair whorl are not shown since no depredation occurred in 2011.

Table 2. Distribution of calf losses by hair whorl pattern, age of cow (ranging from 5 - 17 years) and the overall number of cows per age group.

\begin{tabular}{ccccccccc}
\hline \multicolumn{7}{c}{ Hair Whorl Pattern } \\
\hline Age & n & High & Middle & Low & Abnormal Multiple & None & Overall \\
\hline $\mathbf{5}$ & $\mathbf{1 5 0}$ & - & $\mathbf{2}$ & $\mathbf{3}$ & - & $\mathbf{1}$ & $\mathbf{5}$ & $\mathbf{1 1}$ \\
$\mathbf{6}$ & $\mathbf{1 2 9}$ & - & $\mathbf{6}$ & $\mathbf{2}$ & - & - & $\mathbf{1}$ & $\mathbf{9}$ \\
$\mathbf{7}$ & $\mathbf{8 2}$ & - & - & $\mathbf{1}$ & - & - & - & $\mathbf{1}$ \\
$\mathbf{8}$ & $\mathbf{6 4}$ & $\mathbf{1}$ & $\mathbf{1}$ & - & - & - & $\mathbf{1}$ & $\mathbf{3}$ \\
$\mathbf{9}$ & $\mathbf{4 7}$ & - & - & - & - & - & $\mathbf{1}$ & $\mathbf{1}$ \\
10 & 45 & - & - & - & - & - & - & 0 \\
11 & 24 & - & - & - & - & - & - & 0 \\
$\mathbf{1 2}$ & $\mathbf{1 8}$ & - & - & $\mathbf{1}$ & - & - & - & $\mathbf{1}$ \\
13 & 7 & - & - & - & - & - & - & 0 \\
$\mathbf{1 4}$ & $\mathbf{1 4}$ & - & $\mathbf{4}$ & $\mathbf{1}$ & - & $\mathbf{2}$ & $\mathbf{3}$ & $\mathbf{1 0}$ \\
15 & 4 & - & - & - & - & - & - & 0 \\
16 & 2 & - & - & - & - & - & - & 0 \\
17 & 2 & - & - & - & - & - & - & 0 \\
Overall: 588 & $\mathbf{1}$ & $\mathbf{1 3}$ & $\mathbf{8}$ & $\mathbf{0}$ & $\mathbf{3}$ & $\mathbf{1 1}$ & 36 \\
\hline
\end{tabular}

more time to react and retreat in case of a predator approach. Vigilance is an indicator for fearfulness as shown in dairy cows by Welp et al., 2004 [29]. By being less vigilant and fearful, cows in the present study may have lost their calf to predators.

Cows without a facial HW have a five-time higher probability of losing the calf to predation compared to cows with other HW patterns. In humans, the skin, neural tube and the nervous tissues develop during the third and fourth week of gestation [39] and this is comparable to cattle. Hair follicles start to develop at week 10 and are 
extruded by week 18 of gestation in humans and cattle $[40,41]$. The hair whorl, or cowlick (in humans) can give information about the neuronal development. For simplicity purposes we will refer to cowlicks as hair whorl as well. Failures of proper development during early gestation can lead to a 'hair collar' in humans [39]. Neuronal changes underlying a hair collar can be agenesis of the corpus callosum or a Dandy-Walker malfunction. In humans, abnormal scalp-hair patterning can indicate brain malfunctions [40]. Without a parietal hair whorl, infants show severe brain deficits and most stillborns do not have a parietal HW $[42,43]$. Cows without a facial HW pattern lost more calves than any other group of cows in the present study. The absence of a facial HW pattern may imply that cows without a HW have neuronal aberrations compared to other cows.

While collecting observational data on maternal protectiveness, the first author noted abnormal behaviors of young calves without a HW. The temperament of an animal, measured by the facial $\mathrm{HW}$, has a moderate heritability (German Angus $0.61 \pm 0.17$, Simmental 0.59 \pm 0.41 [44]). Without paternity testing, we are however unable to determine the HW pattern of the calf, since both, the maternal and paternal HW pattern can shape the calf's HW. It is unlikely that paternal behavioral influences occur during the calf's development. Bulls are kept separately from the cow herd and the behavior of calves is most likely shaped by the mothers influence. Cows are hider species and calves stay hidden between bushes during the first days while cows are foraging nearby [45]. The normal reaction of a calf to an approaching unknown object/person is to jump up, call loudly for the mother and to run away. Calves without a HW pattern, on the other hand, kept lying between bushes and allowed the first author to pet them all over the body. In case of an approaching predator this calf would probably die. The high number of calf losses of cows without a facial HW pattern might be a combination of the reduced fear of the calf and possibly lower levels of protection of the cow. Cattle research in Canada identified alterations of the movement pattern and nearest neighbor distance in response to predator presence [46]. Anti-predator behaviors of cattle in the former study seemed, however, erratic and inconsistent. Since most cattle do not experience predation during their lifetime the question arises if the industry is selecting against anti-predator behaviors [47]?

The age of a cow further influenced the probability of losing the calf to predation. The age range of cows observed in this study was 5 - 17 years, with an average of 7.4 years which represents a typical beef herd in the US. (http://www.agtoursusa.com/BeefCattleUSA.htm). Several young cows ( 5 and 6 years of age) lost their calves to predation. Younger cows may have less experience when encountering predators [48] and react unadept. Social animals, such as cattle, are able to learn and alter their behavior based on their own or a conspecifics experience [49]. Usually, wolf depredations increase in later summer (August and September) as shown by [50], whereas bears and coyotes attack younger calves in early summer. Other studies also confirmed that calves younger than 9 months are the most frequent killed animals within the herd [51]. To our knowledge, this is the first study showing an age effect of the mother on the probability of losing the calf to predation. While immature younger cows are at risk during calving (unpublished data), it appears that older cows over the age of 10 years have an increased probability of losing their calf. Anti-predator behaviors are most likely to occur when the predator and prey species naturally occur within the same area. This was found by Parsons et al., 2007 [51], who showed that a familiar predator species (dingo (Canis dingo)) can elicit an anti-predator behavior in gray kangaroos (Macropus giganteus) whereas an unfamiliar predator species (coyote (Canis latrans)) elicits a much weaker response. Here, the inexperience of younger cows (5 and 6 years of age) may have contributed to depredation losses since slightly older cattle show a reduced amount of losses. Ongoing research in the areas of predatorprey/livestock interactions, human-wild-life conflict and animal behavior will be needed to support carnivore conservation and maintain ranch practices.

\section{CONCLUSION}

Temperament selection of livestock species and especially cattle during the last 15 years has led to calm and easy to handle cattle. With the reintroduction of Canadian gray wolves in the Northern Rocky Mountains, ranchers face a new challenge. Without defined protective abilities, losses in cattle have increased since cows perform only minor protective behaviors in response to a predator approach. Our study showed an age and temperament effect on the probability of a cow to lose the calf to predation. The hair whorl pattern (HW) on the forehead of cows was used as a measure of temperament. While cows with high, middle, low abnormal and multiple HWs have an average probability of $0 \%-6.1 \%$ of losing the calf, cows without the facial HW have a greatly increased probability of $19.6 \%$. Further, with increasing age the predation probability increases, too. To our knowledge, this is the first study showing a connection between animal temperament and predation losses in cattle. Further research around livestockpredator interaction needs to be conducted to continue wolf conservation in areas with high predation pressure.

\section{ACKNOWLEDGEMENTS}

We are grateful for the opportunity of visiting the OX Ranch in Idaho; 
the manager Casey Anderson and Doug and Lori McKinney for their hospitality and help during this project. We thank Jim zumBrunnen for statistical help and discussions. This research was funded by Dr. Temple Grandin.

\section{REFERENCES}

[1] Bangs, E.E. and Fritts, S.H. (1996) Reintroducing the Gray Wolf to Central Idaho and Yellowstone National Park. Wildlife Society Bulletin, 24, 402-413.

[2] Ripple, W.J., Larsen, A.J., Renkin, R.A. and Smith, D.W. (2001) Trophic cascade among wolves, elk and aspen on Yellowstone National Park's northern range. Biological Conservation, 102, 227-234. doi:10.1016/S0006-3207(01)00107-0

[3] Ripple, W.J. and Beschta, R.L. (2003) Wolf reintro-duction, predation risk, and cottonwood recovery in Yellowstone National Park. Forest Ecology Management, 184, 299-313. doi:10.1016/S0378-1127(03)00154-3

[4] White, C.A., Olmsted, C.E. and Kay, D.E. (1998) Aspen, elk, and fire in the Rocky Mountain national parks of North America. Wildlife Society Bulletin, 26, 449-462.

[5] Ripple, W.J. and Beschta, R.L. (2004) Wolves, elk, willows, trophic cascades in the upper Gallatin Range of South-western Montana, USA. Forest Ecology Management, 200, 161-181. doi:10.1016/j.foreco.2004.06.017

[6] Beyer, H.L., Merrill, E.H., Varley, N. and Boyce, M.S. (2007) Willow on Yellowstone's northern range: Evidence for a trophic cascade? Ecological Applications, 17, 1563-1571. doi:10.1890/06-1254.1

[7] Smith, D.W., Peterson, R.O. and Houston, D.B. (2003) Yellowstone after wolves. BioOne, 53, 330-340.

[8] Creel, S. and Christianson, D. (2009) Wolf presence and increased willow consumption by Yellowstone elk: Implications for trophic cascades. Ecology, 90, 2454-2466. doi:10.1890/08-2017.1

[9] Bangs, E.E., Fritts, S.H., Fontaine, J.A., Smith, D.W., Murphy, K.M., Mach, C.M. and Niemeyer, C.C. (1998) Status of gray wolf restoration in Montana, Idaho and Wyoming. Wildlife Society Bulletin, 26, 785-798.

[10] Smith, D.W. and Bangs, E.E. (2009) Reintroduction of wolves to Yellowstone National Park: History, values and ecosystem restoration. In: Hayward, M.W. and Somers, M.J., Eds., Reintroduction of Top-Order Predators, Blackwell Publishing.

[11] Fritts, S.H., Stephenson, R.O., Hayes, R.D. and Boitani, L. (2003) Wolves and humans. In: Mech, L.D., Boitani, L. Eds., Wolves: Behavior, Ecology and Conservation, University of Chicago Press, 289-340.

[12] Muhly, T.B. and Musiani, M. (2009) Livestock depredation by wolves and the ranching economy in the Northern US. Ecological Economics, 68, 2439-2450.

[13] Creel, S. and Christianson, D. (2008) Relationships between direct predation and risk effects. Trends in Ecology and Evolution, 23, 194-201. doi:10.1016/j.tree.2007.12.004

[14] Preisser, E.L. and Bolnick, D.I. (2008) The many faces of fear: Comparing the pathways and impacts of nonconsumptive predator effects on prey populations. PLoS One, 3, e2465. doi:10.1371/journal.pone.0002465

[15] Fortin, D., Beyer, H.L., Boyce, M.S., Smith, D.W., Duchesne, T. and Mao, J.S. (2005) Wolves influence elk movements: Behavior shapes a trophic cascade in Yellowstone National Park. Ecology, 86, 1320-1330. doi:10.1890/04-0953

[16] Creel, S., Winnie, J.A.J., Maxwell, B., Hamlin, K. and Creel, M. (2005) Elk alter habitat selection as an antipredator response to wolves. Ecology, 86, 3387-3397. doi:10.1890/05-0032

[17] Mao, J.S., Boyce, M.S., Smith, D.W., Singer, F.J., Vales, D.J., Vore, J.M. and Merrill, E.H. (2005) Habitat selection by elk before and after wolf reintroduction in Yellowstone National Park. Journal of Wildlife Management, 69, 1691-1707.

doi:10.2193/0022-541X(2005)69[1691:HSBEBA]2.0.CO ;2

[18] Hebblewhite, M. and Pletscher, D.H. (2002) Effect of elk group size on predation by wolves. Canadian Journal of Zoology, 80, 800-809. doi:10.1139/z02-059

[19] Creel, S. and Winnie, J.A.J. (2005) Responses of elk herd size to fine-scale spatial and temporal variation in the risk of predation by wolves. Animal Behaviour, 69, 1181-1189. doi:10.1016/j.anbehav.2004.07.022

[20] Jayakody, S., Sibbald, A.M., Gordon, I.J. and Lambin, X. (2008) Red deer Cervus elephus vigilance behaviour differs with habitat and type of human disturbance. Wildlife Biology, 14, 81-91. doi:10.2981/0909-6396(2008)14[81:RDCEVB]2.0.CO;2

[21] Berger, J., Swenson, J.E. and Persson, I.L. (2001) Recolonizing carnivores and naïve prey: Conservation lesson from Pleistocene extinctions. Science, 291, 1036-1039. doi:10.1126/science.1056466

[22] Laundré, J.W., Hernanadez, L. and Altendorf, K.B. (2001) Wolves, elk, and bison: Reestablishing the "landscape of fear" in Yellowstone National Park, USA. Canadian Journal of Zoology, 79, 1401-1409. doi:10.1139/z01-094

[23] Hamel, S. and Coté, S.D. (2008) Trade-offs in activity budget in an alpine ungulate: Contrasting lactating and nonlactating females. Animal Behaviour, 75, 217-227. doi:10.1016/j.anbehav.2007.04.028

[24] Li, Z. and Jiang, Z. (2008) Group size effect on vigilance: evidence from Tibetan gazelle in Upper Buha River, Qinghai-Tibet Plateau. Behavioural Processes, 78, 25-28. doi:10.1016/j.beproc.2007.11.011

[25] Musiani, M., Murphy, T., Gates, C.C., Callaghan, C., Smith, M.E. and Tosoni, E. (2005) Seasonality and reoccurrence of depredation and wolf control in Western North America. Wildlife Society Bulletin, 33, 876-887. doi:10.2193/0091-7648(2005)33[876:SARODA]2.0.CO; $\underline{2}$

[26] Price, E.O. (1984) Behavioral aspects of animal domestication. The Quarterly Review of Biology, 59, 1-32. doi:10.1086/413673

[27] Diamond, F. (2002) Evolution, consequences and future of plant and animal domestication. Nature, 418, 700-707. 


\section{doi:10.1038/nature01019}

[28] Price, E.O. (2002) Predation, infectious diseases and parasites. In: Price, E.O., Ed., Animal Domestication and Behavior, CABI Publishing, New York, 107-112. doi:10.1079/9780851995977.0107

[29] Welp, T., Rushen, J., Kramer, D.L., Festa-Bianchet, M. and de Passillé, A.M.B. (2004) Vigilance as a measure of fear in dairy cattle. Applied Animal Behaviour Science, 87, 1-13. doi:10.1016/j.applanim.2003.12.013

[30] Kluever, B.M., Howery, L.D., Breck, S.W. and Bergmann, D.L. (2009) Predator and heterospecific stimuli alter behaviour in cattle. Behavioural Processes, 81, 85-91. doi:10.1016/j.beproc.2009.02.004

[31] Flörcke, C., Engle, T.E., Grandin, T. and Deesing, M.J. (2012) Individual differences in calf defence patterns in Red Angus beef cows. Applied Animal Behavior Science, 139, 203-208. doi:10.1016/j.applanim.2012.04.001

[32] Grandin, T., Deesing, M.J., Struthers, J.J. and Swinker, A.M. (1995) Cattle hair whorl patterns above the eyes are more behaviorally agitated during restraint. Applied Animal Behaviour Science, 46, 117-123. doi:10.1016/0168-1591(95)00638-9

[33] Randle, H.D. (1998) Facial hair whorl position and temperament in cattle. Applied Animal Behaviour Science, 56, 139-147. doi:10.1016/S0168-1591(97)00086-5

[34] Hyde, L. (2010) Limousine Breeders tackle temperament - genetic trend shows power of selection. http://www.nalf.org/pdf/2010/aug19/tackletemperament

[35] Voisinet, B.D., Grandin, T., Tatum, J.D., O’Connor, S.F. and Struthers, J.J. (1997) Feedlot cattle with calm temperaments have higher average daily gains than cattle with excitable temperaments. Journal of Animal Science, 75, 892-896.

[36] Boivin, X., Le Neindre, P. and Chupin, J.M. (1992) Establishment of cattle-human relationships. Applied Animal Behaviour Science, 32, 325-335. doi:10.1016/S0168-1591(05)80025-5

[37] Grandin, T. (1997) Assessment of stress during handling and transport. Journal of Animal Science, 75, 249-257.

[38] Brouček, J., Uhrinčat, M., Šoch, M. and Kišac, P. (2008) Genetics of behaviour in cattle. Slovakian Journal of Animal Science, 41, 166-172.

[39] Drolet, B.A., Clowry Jr., L., Mc Tigue, M.K. and Esterly, N.B. (1995) The hair collar sign: Marker of cranial dysraphism. Pediatrics, 96, 309-313.

[40] Smith, D.W. and Gong, B.T. (1973) Scalp hair patterning as a clue to early fetal brain development. Pediatrics, 83,

\section{4-380. doi:10.1016/S0022-3476(73)80258-6}

[41] Smith, D.W. and Greely, M.J. (1978) Unruly scalp hair in infants: Its nature and relevance to problems of brain morphogenesis. Pediatrics, 61, 783-785.

[42] Higginbottom, M.C., Jones, K.L., Hall, B.D. and Smith, D.W. (1979) The amniotic band disruption complex: Timing of amniotic rupture and variable spectra of consequent defects. Pediatrics, 95, 544-549. doi:10.1016/S0022-3476(79)80759-3

[43] Faye-Petersen, O., David, E., Rangwala, N., Seaman, J.P., Hua, Z. and Heller, D.S. (2006) Otocephaly: Report of five new cases and a literature review. Fetal and Pediatric Pathology, 25, 277-296. doi:10.1080/15513810601123417

[44] Gauly, M., Mathiak, H., Hoffman, K., Kraus, M. and Erhardt, G. (2001) Estimating genetic variability in temperamental traits in German Angus and Simmental cattle. Applied Animal Behaviour Science, 74, 109-119. doi:10.1016/S0168-1591(01)00151-4

[45] Langbein, J. and Raasch, M.L. (2000) Investigations on the hiding behaviour of calves at pasture. Archiv der Tierzucht, 43, 203-210.

[46] Price, E.O. (1999) Behavioral development in animals undergoing domestication. Applied Animal Behaviour Science, 65, 245-271. doi:10.1016/S0168-1591(99)00087-8

[47] Laporte, I., Muhly, T.B., Pitt, J.A., Alexander, M. and Musiani, M. (2010) Effects of wolves on elk and cattle behaviors: Implications for livestock production and wolf conservation. PlosOne, 5, e11954. doi:10.1371/journal.pone.0011954

[48] Griffin, A.S. (2004) Social learning about predators: A review and prospectus. Animal Learning and Behavior, 32, 131-140. doi:10.3758/BF03196014

[49] Dorrance, M.J. (1982) Predation losses of cattle in Alberta. Journal of Range Management, 35, 690-692. doi:10.2307/3898239

[50] Palmeira, F.B.L., Crawshaw Jr., P.G., Hahhad, C.M., Ferraz, K.M.P.M.B. and Verdade, L.M. (2008) Cattle depredation by puma (Puma concolor) and jaguar (Panthera onca) in central-western Brazil. Biological Conservations, 141, 118-125. doi:10.1016/j.biocon.2007.09.015

[51] Parsons, M.H., Lamont, B.B., Kovacs, B.R. and Davies, S.J.F. (2007) Effects of novel and historic predator urines on semi-wild western grey kangaroos. Journal of Wildlife Management, 71, 1225-1228.

http://www.agtoursusa.com/BeefCattleUSA.htm 